\title{
Prevalence of IgE-mediated allergy and evaluation of Th1/Th2 cytokine profiles in patients with severe bronchial asthma
}

\author{
Barbara Rogala ${ }^{1}$, Andrzej Bozek², Joanna Gluck ${ }^{1}$, Jerzy Jarzab² \\ ${ }^{1}$ Chair and Clinical Department of Internal Diseases, Allergology and Clinical Immunology, Medical University of Silesia, Katowice, \\ Poland \\ Head of the Department: Prof. Barbara Rogala MD, PhD \\ ${ }^{2}$ Chair and Clinical Department of Internal Medicine, Dermatology and Allergology, Medical University of Silesia, Zabrze, Poland \\ Head of the Department: Prof. Jerzy Jarzab MD, PhD
}

\begin{abstract}
Introduction: The pathogenesis of asthma remains unclear, especially in cases of the severe disease.

Aim: To explore IgE-mediated inhalant sensitization in severe asthma compared with a group of patients with chronic mild disease and evaluate the Th1/Th2 cytokine profiles in asthma by different disease severities.

Material and methods: One hundred and fifty-four patients (age range: 28-69) with severe chronic asthma (study group) and 141 patients with chronic mild disease (control group) diagnosed according to GINA criteria were included in the study. Seventy-eight severe asthmatics and 43 subjects with mild disease were randomly selected for serum Th1/Th2 cytokine level estimation. The groups were matched in terms of age and atopy features (skin prick tests, specific and total serum IgE).

Results: Positive skin tests to at least one allergen were observed with comparable frequencies. Sensitization to Dermatophagoides pteronyssinus was the most prevalent positive result in both groups. An earlier onset of asthma together with a greater number of exacerbations was noted in severe asthmatics compared to patients with mild disease. Serum levels of interleukin 4 and 2 (IL-4 and IL-2) were detectable only in severe asthmatics irrespective of atopy features. The levels of interferon $\gamma$ and tumour necrosis factor $\alpha$ were undetectable in both groups. IL-10 and IL-5 were detected in the serum of only 7 and 12 severe asthmatics, respectively.

Conclusions: The serum level of IL-2 and IL- 4 could be perceived as a marker of severe asthma. Neither IL-2 nor IL-4 levels in the serum could differentiate allergic and non-allergic asthma.
\end{abstract}

Key words: severe asthma, immunoglobulin E, Th1/Th2.

\section{Introduction}

Bronchial asthma has a very complex pathogenesis [1-3]. It is an immunologically driven disorder that is influenced by the environment and by epigenetic phenomena. Although IgE-mediated sensitivity to common aeroallergens is the strongest identifiable predisposing factor to the development of asthma, particularly in children [4-7], confusion still exists over the precise role of this association in many asthmatics. This is particularly the case of severe asthma [8-10]. The crucial cells in the inflammatory infiltrate of the airway are driven by a subset of T lymphocytes that secrete a panel of cytokines. All of the types of asthma, regardless of the allergic back- ground, display a Th2/Tc2 profile. Interleukin 4 (IL-4) is critical for committing both CD4+ and CD8+ T cells to Th2 and Tc2 phenotypes [11-14]. It is worth noting that atopic rhinitis subjects who have not been exposed to the offending allergens have a largely reduced Th2 response compared to patients with established asthma [15, 16]. Nevertheless, the immunopathophysiology of asthma extends beyond a simple Th2-driven inflammatory disorder. This phenomenon raises a question of whether peripheral blood immune cells of severe asthmatic patients have the capacity to differentiate the disorder as allergic or non-allergic.

Address for correspondence: Andrzej Bozek MD, PhD, Chair and Clinical Department of Internal Medicine, Dermatology and Allergology, Medical University of Silesia, 10 M. Skłodowskiej-Curie St, 41-800 Zabrze, Poland, phone/fax: +48 3227131 65,

e-mail: andrzejbozek@o2.pl

Received: 25.12.2014, accepted: 6.02.2015. 
Aim

The aim of this study was to assess the prevalence of IgE-mediated inhaled allergy/sensitization in patients with severe, difficult-to-control asthma compared to a group of patients with a chronic mild course of the disease. An additional aim of the study was to compare the Th1/Th2-type cytokine profile (IL-2, IL-4, IL-5, IL-10, tumor necrosis factor $\alpha$ (TNF- $\alpha$ ), and interferon $\gamma($ IFN- $\gamma$ )) in the serum of asthma patients depending on the disease severity.

\section{Material and methods}

\section{Patients}

One hundred and fifty-four patients with severe asthma diagnosed according to GINA criteria were included in the study. There were 69 women and 89 men with a mean age of $54.3 \pm 11.6$ (range: $28-69$ ) years. The detailed personal, family and disease history was assessed via an original questionnaire based on the European Community Respiratory Health Survey Asthma Questionnaire (ECRH). Patients with chronic obstructive pulmonary disease (COPD) and/or other inflammatory chronic diseases were excluded from the study. The characteristics of the respondents are presented in Table 1. One hundred and forty-one patients with chronic mild asthma according to GINA criteria constituted the control group (59 women, 82 men, mean age $52.9 \pm 9.2$ years, range: $25-71$ years). The studied groups were matched according to age and gender.

In addition, a subgroup of 78 patients with severe bronchial asthma (37 women and 41 men) and $43 \mathrm{pa}-$ tients (18 women and 25 men) with mild bronchial asthma were randomly selected to have serum Th1/ Th2 cytokine levels assessed. They were further divided into two groups based on the findings for atopy, i.e., skin prick tests and/or serum allergen-specific IgE levels. There were 37 and 41 patients with and without at- opy features in the severe bronchial asthma group and 29 and 14 patients with and without atopy features in the mild bronchial asthma group, respectively. Both groups were comparable in terms of age and prevalence of atopy features. The study was approved by the Local Ethical Committee of the Medical University of Silesia.

\section{Diagnostic procedures}

\section{Skin prick test}

The skin prick test with common aeroallergens (D. pteronyssinus, D. farinae, grass, rye, birch, alder, hazel, mugwort, Alternaria sp., Cladosporium sp., Aspergillus sp., cat, dog) was performed using a diagnostic commercial test (Allergopharma, Germany). Positive $(10 \mathrm{mg} / \mathrm{ml}$ histamine) and negative (saline control) control tests were performed. The positive results was defined as having a positive skin test for at least one allergen with a maximum wheal diameter that was at least $3 \mathrm{~mm}$ larger than that of the negative control.

\section{Total and specific IgE level estimation}

The specific serum IgE (slgE) level against the allergens mentioned above was measured using the immunoenzymatic method Poly - Check (Immunogenetics, US). The results were assessed as positive when the serum slgE concentration was $>0.7 \mathrm{IU} / \mathrm{ml}$ (class II according to the manufacturer's brochure). The total IgE in the serum was measured using an ECLIA test (Roche Diagnostics), and the values are presented in $\mathrm{IU} / \mathrm{ml}$.

\section{Serum Th1/Th2 cytokine level estimation}

To identify the Th1/Th2 profile, the concentrations of IL-2, IL-4, IL-5, IL-10, TNF- $\alpha$, and IFN- $\gamma$ in serum were measured using a human Th1/Th2 cytokine kit II (ImmunoGEN, US) and a FacsCalibur flow cytometer (Becton Dickinson, US) according to the manufacturer's instruc-

Table 1. Characteristics of the respondents

\begin{tabular}{|c|c|c|c|}
\hline Characteristics & $\begin{array}{l}\text { Severe asthma } \\
\qquad(N=154)\end{array}$ & $\begin{array}{l}\text { Mild asthma - control group } \\
\qquad(N=141)\end{array}$ & Value of $p$ \\
\hline Duration of asthma, mean \pm SD [years] & $24.3 \pm 7.5$ & $16.1 \pm 8.3$ & $<0.05$ \\
\hline Positive history of allergy & $98(63.6 \%)$ & $114(80.8 \%)$ & $<0.05$ \\
\hline Family asthma & $104(60 \%)$ & $87(61.7 \%)$ & NS \\
\hline Allergies in the family & $86(55.8 \%)$ & $54(38.3 \%)$ & $<0.05$ \\
\hline Concomitant rhinitis & $109(70.8 \%)$ & $123(87 \%)$ & $<0.05$ \\
\hline Atopic dermatitis & $16(10.4 \%)$ & $21(14.9 \%)$ & NS \\
\hline $\mathrm{FEV}_{1}$ (\% of norm according to ATS) & 58.4 & 79.8 & $<0.05$ \\
\hline FVC (\% of norm according to ATS) & 69.3 & 90.5 & $<0.05$ \\
\hline Current smoker & $22(14.3 \%)$ & $43(30.5 \%)$ & $<0.05$ \\
\hline Former smoker & $62(40.3 \%)$ & $35(24.8 \%)$ & $<0.05$ \\
\hline Higher education & $47(30.5 \%)$ & $36(25.5 \%)$ & NS \\
\hline
\end{tabular}


tions. The sensitivity of the measurements were as follows: IL-2 > $31.2 \mathrm{pg} / \mathrm{ml}$; IL-4 > $10 \mathrm{pg} / \mathrm{ml}$; IL-5 > $5.1 \mathrm{pg} /$ $\mathrm{ml} ; \mathrm{IL}-10>11.6 \mathrm{pg} / \mathrm{ml} ; \mathrm{IL}-13>13.6 \mathrm{pg} / \mathrm{ml}$; TNF- $\alpha$ $>6.5 \mathrm{pg} / \mathrm{ml}$; and IFN- $\gamma>5.2 \mathrm{pg} / \mathrm{ml}$.

\section{Statistical analysis}

The results are expressed as median values with interquartile ranges or as a percentage. Nonparametric tests were used; the Mann-Whitney U rank-sum test and Spearman's correlation test were used for continuous variables, and the $\chi^{2}$ test was used for categorical variables. All of the analyses were performed with a software package (The Quick Statistica v.5.l). Values of $p$ less than 0.05 were considered significant. Summary odds ratios and 95\% confidence intervals and standard errors using random-effects models were computed.

\section{Results}

The onset of asthma occurred much earlier in the group of patients with severe asthma than in those suffering from a mild form of the disease. The following risk factors for severe asthma were demonstrated: an adjusted odds ratio for the age of the patient of 1.8 (95\% confidence interval (CI): 1.1-2.3), an odds ratio (OR) for male gender of 1.5 (95\% Cl: 0.9-1.9), an OR for smoking of 2.2 (95\% Cl: 1.6-2.5) and an OR for a lower level of education of 1.3 (95\% Cl: 0.8-1.7).

A history of allergy was noted in 98 (63.6\%) patients in the group with severe asthma and in 114 (80.8\%) patients with mild asthma; this difference was statistically significant (Table 1).

In the group with severe asthma, significantly more asthma exacerbations were observed in asthmatics with- out atopy than in the patients with IgE-mediated sensitization (2.3/patient/year vs. 1.5/patient/year, respectively, $p<0.05)$. A similar relationship was observed in the control group (1.8/patient/year vs. 1.1/patient/year, respectively, $p<0.05)$.

A positive skin test result to at least one allergen was demonstrated in 125 (81.2\%) patients with severe asthma, which was slightly less than that observed in the control group (119 (84.4\%)). The difference was not statistically significant $(p<0.05)$.

The highest incidence of sensitization among the tested allergens was demonstrated for Dermatophagoides pteronyssinus/farinae for patients with severe asthma and grass, and rye for patients with mild asthma (Table 2).

A similar correlation was observed in serum concentrations of specific lgE between analyzed groups. However, there were no such significant differences regarding D. pteronyssinus and D. farinae (Table 3).

Additionally, the elevated levels of allergen-specific IgE against the tested allergens significantly correlated with the results of the skin tests in severe asthmatics and in patients with mild asthma (Spearman's coefficient $R$ in the range of 0.69-0.87, $p<0.05$ ).

Allergen-specific IgE sensitivity against at least one of the allergens in the tested panel was noted in both groups in similar numbers of patients ( $84 \%$ of severe asthmatics and $86 \%$ of mild asthmatics, $p=0.65$ ).

\section{Concentrations of total serum IgE}

The average concentration of total IgE in the study group was $77.8 \pm 24.8$ (range: $3.6-884.2$ ) IU/ml and was significantly lower than in the control group $(89.2 \pm 34.1$ $\mathrm{IU} / \mathrm{ml}$, range $5.9-1450.4 \mathrm{IU} / \mathrm{ml}, p<0.05)$. In the study

Table 2. Comparison of positive results for skin prick tests (SPT) in the study and the control groups

\begin{tabular}{|c|c|c|c|}
\hline SPT against allergens & $\begin{array}{l}\text { Severe asthma } \\
\qquad(N=154)\end{array}$ & $\begin{array}{l}\text { Mild asthma - control group } \\
\qquad(N=141)\end{array}$ & Value of $p$ \\
\hline D. pteronyssinus & $57(37.1 \%)$ & $48(34.2 \%)$ & NS \\
\hline D. farinae & 49 (32.4\%) & $43(30.5 \%)$ & NS \\
\hline Grass & $34(22 \%)$ & $58(41.3 \%)$ & $<0.05$ \\
\hline Rye & 37 (24.1\%) & $59(41.8 \%)$ & $<0.05$ \\
\hline Birch & $33(21.4 \%)$ & $38(27 \%)$ & NS \\
\hline Alder & $21(13.6 \%)$ & 25 (17.7\%) & NS \\
\hline Hazel & $20(13 \%)$ & $23(16.3 \%)$ & NS \\
\hline Mugwort & $15(9.7 \%)$ & 19 (13.5\%) & NS \\
\hline Alternaria & $30(19.4 \%)$ & $11(7.8 \%)$ & $<0.05$ \\
\hline Cladosporium & 11 (7.1\%) & $6(4.3 \%)$ & NS \\
\hline Aspergillus & $14(9.1 \%)$ & $8(5.7 \%)$ & NS \\
\hline Cat & $17(11.2 \%)$ & $14(9.9 \%)$ & NS \\
\hline Dog & $9(5.8 \%)$ & $7(5 \%)$ & NS \\
\hline
\end{tabular}


Table 3. Comparison of positive results for allergen-specific IgE in the study group and the control group

\begin{tabular}{lccc}
\hline slgE against allergens & $\begin{array}{c}\text { Severe asthma } \\
(N=154)\end{array}$ & $\begin{array}{c}\text { Mild asthma - control group } \\
(N=141)\end{array}$ & Value of $p$ \\
\hline D. pteronyssinus & $63(40.9 \%)$ & $54(38.3 \%)$ & NS \\
\hline D. farinae & $52(33.8 \%)$ & $46(32.6 \%)$ & NS \\
\hline Grass & $39(25.3 \%)$ & $55(39 \%)$ & $<.05$ \\
\hline Rye & $32(20.8 \%)$ & $52(36.8 \%)$ & NS \\
\hline Birch & $34(22.1 \%)$ & $39(27.7 \%)$ & NS \\
\hline Alder & $18(11.7 \%)$ & $24(17.1 \%)$ & NS \\
\hline Hazel & $20(13 \%)$ & $21(14.9 \%)$ & NS \\
\hline Mugwort & $17(11 \%)$ & $20(14.1 \%)$ & $<0.05$ \\
\hline Alternaria & $28(18.2 \%)$ & $14(9.9 \%)$ & NS \\
\hline Cladosporium & $12(7.8 \%)$ & $7(5.0 \%)$ & NS \\
\hline Aspergillus & $13(8.4 \%)$ & $10(7.1 \%)$ & NS \\
\hline Cat & $19(12.3 \%)$ & $14(9.9 \%)$ & NS
\end{tabular}

group, there was a positive correlation between smoking and the total IgE concentration $(R=0.97, p<0.05)$.

There was a negative correlation between the serum concentrations of total lgE and the forced expiratory volume in $1 \mathrm{~s}\left(\mathrm{FEV}_{1}\right)$ value both in the study group and in the control group $(R=-0.83, p<0.05)$. There was no correlation between serum total IgE and the duration of asthma.

\section{Serum levels of cytokines}

The serum levels of IFN- $\gamma$ and TNF- $\alpha$ were undetectable in both groups, and those of IL-4 and IL-2 were undetectable in mild asthmatics. Serum levels of IL-10 and IL-5 were detectable only in 7 and 12 cases in severe asthmatics and in 1 and 6 patients, respectively, in mild asthmatics. As a result, these data were excluded from further analyses, and comparisons between the two groups of asthma patients were not possible. Additional analyses were performed only in the former group.

Serum levels of IL-4 and IL-2 were detectable in 37 atopy cases and in 41 non-atopic cases in severe asthma patients. The median and interquartile ranges for the serum levels of IL-4 in the atopic and non-atopic patients in the severe bronchial asthma group were as follows: 2.57; $1.96-3.55 \mathrm{pg} / \mathrm{ml}$ and $2.17 ; 1.27--3.16 \mathrm{pg} / \mathrm{ml}$, respectively. They did not differ between the groups. The median and interquartile ranges for the serum levels of IL-2 in atopic and non-atopic patients were as follows: 6.76; $5.55-7.56 \mathrm{pg} / \mathrm{ml}$ and $7.16 ; 5.96-7.95 \mathrm{pg} / \mathrm{ml}$, respectively. They did not differ between the groups.

\section{Total IgE levels in the analyzed subgroup}

The total IgE serum levels in atopic and non-atopic patients were as follows: $139.4 \mathrm{kU} /$; range: $89.78-$ 314.95 and $23.11 \mathrm{kU} /$; range $12.6-45.3$, respectively. They were significantly higher in atopic patients $(p<0.001)$. Correlations between total IgE serum levels and IL-4 or IL-2 serum levels both in the whole group of patients and in the atopic and non-atopic patients were not significant.

\section{Discussion}

We discovered some clinical features that differentiate patients with severe asthma from those suffering from a mild form of the disease. Patients with severe asthma have a more frequent positive family history of allergy and a longer personal history of asthma. Patients who suffer from mild asthma show a much more frequent positive personal history of allergy and concomitant rhinitis than individuals with severe disease. Current smokers were observed more often among mild asthmatics, but former smokers were more common in those with severe disease [17].

An interesting observation of our study was a more common loss of asthma control in subjects without IgE-dependent sensitization. Moreover, this association was observed independently of the asthma severity. Thus, it provides evidence that the course of non-allergic asthma is less stable than allergic asthma, consistent with other observations [4]. 
In the vast majority of patients, sensitization to D. pteronyssinus was noted without a significant difference between the groups. It is well-known that sensitization to perennial allergens is a characteristic of asthma patients. Seasonal allergens more frequently cause allergic rhinitis. Comparable results obtained for aeroallergen sensitization in both groups refutes the hypothesis that sensitization determines the severity of asthma and, concomitantly, confirms the substantial role of IgE-dependent allergy in the pathophysiology of asthma.

A shift in the Th1/Th2 imbalance of the immune system towards the pro-allergenic Th2 response results in the clinical expression of allergy and/or asthma. T helper type $1 \mathrm{~T}$ cells are involved in many inflammatory diseases other than allergic inflammation. T helper type 2 cells express a panel of cytokines including IL-4, IL-3, IL-10, IL-13 and granulocyte-macrophage colony-stimulating factor (GM-CSF). T helper type 1 cells are recognized by IL-2, IFN- $\gamma$, and TNF- $\alpha$, which they release $[11,18]$. These data justify the choice of cytokines evaluated in our study to determine whether the polarization of the Th2/Th1 response at the serum level could differentiate allergic and non-allergic asthma and/or its severity.

The clinical picture of asthma and the changes in airway structure and function are driven by a wide array of cytokines derived both from bone marrow and non-bone marrow cells of the innate immune system. These biologically active proteins determine a wide array of cellular functions such as activation, proliferation, chemotaxis, immunomodulation, and the release of other cytokines or mediators in individuals with asthma [11].

A large amount of research over the last 30 years investigating the pathogenesis of asthma has focused on the roles of cytokines. There are data evaluating the correlation between cytokine production and cytokine gene expression in the blood, bronchoalveolar lavage (BAL) and induced/sputum of patients with asthma. Cytokine production by a lung segment has been shown to occur following allergen challenge. An increased gene expression or secretion of IL-4, IL-5, IL-13, and GM-CSF has been demonstrated in most studies validating the role of the Th2 pathway in airway inflammation in asthmatics [11, 19].

Despite a growing amount of information on the biological activities of cytokines and their involvement in the pathogenesis of asthma, information regarding the day-to-day cytokine profiles of patients with asthma remains sparse. Little is known about the stratification of cytokines in clinical stages of asthma despite the increasing numbers of studies focusing on the immunoregulatory polarization of T cells into Th2 cells. Nevertheless, it is worth emphasizing that the clear distinction between Th1 and Th2 cells is not as distinctive in humans as in animal models $[19,20]$. Moreover, most murine cytokine studies have investigated whether cytokines are important for asthma induction, whereas studies of human cytokines have investigated the role of cytokines in disease maintenance in individuals with asthma. The question is whether there are any differences in the cytokine profile among different clinical asthma phenotypes. One can assume that the severity of asthma is related to differential cytokine patterns in the serum.

\section{Interleukin-4}

Although the primary signal for the activation of these cells is not exactly known, IL-4 is commonly accepted to play a crucial role in driving the differentiation of CD4+Th precursors into Th2-like cells [21]. Apart from determining IgE synthesis by B lymphocytes, this cytokine increases the expression of an inducible form of the low-affinity receptor for IgE (FceRII/CD23) on B lymphocytes and macrophages, which in turn enhances antigen presentation by $\mathrm{B}$ cells. The lack of lung eosinophilia in IL-4 knock-out mice that have been sensitized and exposed to ovalbumin reflects the role of IL-4 in airway hyper-responsiveness, allergic inflammation and, in turn, chronic asthma symptoms. However, some mouse studies have noted that inhalation of recombinant human IL-4 induces airway hyper-responsiveness and sputum eosinophilia $[19,20]$. These data indicate an important role for IL-4 in the pathophysiology of asthma and the appearance of disease symptoms. Our results demonstrating detectable levels of this cytokine in the serum of patients with severe asthma confirm these data.

\section{Interleukin-2}

Interleukin-2 is a potent pro-inflammatory cytokine that causes a significant increase in the influx of eosinophils, lymphocytes and mast cells into the airways. The major sources of IL-2 are activated Th0 and Th1 T cells. Interleukin-2 stimulates the growth and differentiation of T cells, B cells and NK cells, as well as immunoglobulins secretion by B cells. An increased level of IL-2 is observed in the BAL fluid of patients with symptomatic asthma [22]. The important role of these cytokines in the maintenance of inflammatory processes in the airways was demonstrated. It simultaneously explains the role of IL-2 in asthma phenomena [11, 22]. Interleukin-4 and IL-2 reflect the activity of two different subtypes of T cells: Th1 and Th2. The presence of these cytokines in the serum of patients with asthma provides evidence, although indirectly, for the involvement of both Th1 and Th2 cells in the pathophysiology of asthma. It is the case with regard to severe asthma. However, it is worth noting that the ongoing inflammatory processes in the airways of patients with mild disease are reduced compared to those with severe disease, and IL-4 and IL-2 could not be estimated in the serum of these patients.

Among the several analyzed cytokines reflecting the activity of different T cell subsets, only IL-4 and IL-2 were detectable with a comparable frequency in either allergic or non-allergic patients with severe asthma. This result supports the dominant role of these cytokines in the 
pathophysiology of asthma regardless of the IgE-dependent sensitization [23]. Nevertheless, the serum levels of both IL-4 and IL-5 could differentiate the course of asthma because these cytokines were under the level of detection in the serum of patients with mild asthma. Because they were detected only in the serum of patients with a severe form of disease, one can assume that they reflect the intensity of the inflammatory process in the airways.

Although the total IgE serum level was significantly lower in the group of patients with severe asthma, there was no correlation of this immunoglobulin with either IL-4 or IL-2. In this context, it is worth noting that although the level of total IgE was significantly lower in subjects with severe asthma, this difference was not clinically significant.

All patients with asthma have allergic inflammation. It is commonly accepted that allergic inflammation in the airways is ongoing regardless of the severity of the disease, but the intensity of this process is different [14]. It explains the differences in serum levels of IL-4 and IL-2 in both groups of asthmatics. The robustness of the inflammatory process in the airways of patients with mild asthma is likely too low to be reflected by the detectable levels of this cytokine in the serum.

It should be considered that IL-4 and IL-2 reflect the activity of two subsets of T cells. Th2 overactivation characterizes asthma phenomena, but the Th1 response is involved in the maintenance of the asthma process [11]. Our results confirm such approaches to investigating the pathophysiology of asthma.

It is difficult to draw straightforward conclusions from the present results considering a relatively low sensitivity of the methods used for the estimation. A limitation of this study was the methods used to determine the levels of cytokines. In contrast to tissue culture supernatant, the measurement of cytokines in serum is difficult to characterize in multiplexed formats due to the presence of large dynamic concentration ranges of proteins and other interfering factors that are present in this matrix. However, some data highlight a good reliability of this method [24].

\section{Conclusions}

IgE-mediated inhaled allergy plays an important role in patients with severe asthma. Serum levels of either IL-2 or IL-4 can be perceived as a marker of severe asthma.

\section{Conflict of interest}

The authors declare no conflicts of interest.

\section{References}

1. Custovic A, Johnston SL, Pavord I, et al. EAACI position statement on asthma exacerbations and severe asthma. Allergy 2013; 68: 1520-31.
2. Reddy D, Little FF. Glucocorticoid-resistant asthma: more than meets the eye. J Asthma 2013; 50: 1036-44.

3. Rutkowski K, Sowa P, Rutkowska-Talipska J, et al. Allergic diseases: the price of civilisational progress. Postep Derm Alergol 2014; 31: 77-83.

4. Ogershok PR, Warner DJ, Hogan MB, Wilson NW. Prevalence of pollen sensitization in younger children who have asthma. Allergy Asthma Proc 2007; 28: 654-8.

5. Gawlik R, Czecior E, Jarząb J, et al. Frequency of IgE-dependent hypersensitivity to moulds in patients with chronic rhinosinusitis with polyps. Postep Derm Alergol 2014; 31: 159-63.

6. Żukiewicz-Sobczak WA, Chmielewska-Badora J, Wróblewska P, Zwoliński J. Farmers' occupational diseases of allergenic and zoonotic origin. Postep Derm Alergol 2013; 30 : 311-5.

7. Żukiewicz-Sobczak WA, Cholewa G, Krasowska E, et al. Rye grains and the soil derived from under the organic and conventional rye crops as a potential source of biological agents causing respiratory diseases in farmers. Postep Derm Alergol 2013; 30: 373-80.

8. Brightling CE, Gupta S, Hollins F, et al. Immunopathogenesis of severe asthma. Curr Pharm Des 2011; 17: 667-73.

9. Krohn IK, Sverrild A, Lund G, et al. Cultured mast cells from patients with asthma and controls respond with similar sensitivity to recombinant Der p2-induced, IgE-mediated activation. Scand I Immunol 2013; 78: 352-6.

10. Pawankar R, Canonica GW, Holgate ST, Lockey RF. Allergic diseases and asthma: a major global health concern. Curr Opin Allergy Clin Immunol 2012; 12: 39-41.

11. Ngoc PL, Gold DR, Tzianabos AO, et al. Cytokines, allergy and asthma. Curr Opin Allergy Clin Immunol 2005; 5: 161-6.

12. Shirai T, Inui N, Suda T, Chida K. Correlation between peripheral blood T-cell profiles and airway inflammation in atopic asthma. J Allergy Clin Immunol 2006; 118: 622-6.

13. Raeiszadeh Jaromi S, Mahesh PA, Jayaraj BS, et al. Serum levels of IL-10, IL-17F and IL-33 in patients with asthma: a case-control study. J Asthma 2014; 18: 1-10.

14. Holgate ST. Immune circuits in asthma. Curr Opin Pharmacol 2013; 13: 345-50.

15. Glück J, Rogala B, Mazur B. Intracellular production of IL-2, IL-4 and IFN-gamma by peripheral blood CD3+ cells in intermittent allergic rhinitis. Inflamm Res 2005; 54: 91-5.

16. Rondón C, Campo P, Togias A, et al. Local allergic rhinitis: concept, pathophysiology, and management. J Allergy Clin Immunol 2012; 129: 1460-7.

17. Gusbin N, Garzaniti N, Louis R. Asthma and tobacco. Rev Med Liege 2006; 61: 81-6.

18. Shirai T, Inui N, Suda T, Chida K. Correlation between peripheral blood T-cell profiles and airway inflammation in atopic asthma. J Allergy Clin Immunol 2006; 118: 622-6.

19. Finkelman F, Hogan S, Gurjit K, et al. Importance of cytokines in murine allergic airway disease and human asthma. J Immunol 2010; 184: 1663-74.

20. Finkelman FD, Wills-Karp M. Usefulness and optimization of mouse models of allergic airway disease. J Allergy Clin Immunol 2008; 121: 603-6.

21. Wenzel S, Wilbraham D, Fuller R, et al. Effect of an interleukin-4 variant on late phase asthma response to allergen challenge in asthmatic patients: results of two phase II studies. Lancet 2007; 370: 1396-8. 
22. Boomer JS, Parulekar AD, Patterson BM, et al. A detailed phenotypic analysis of immune cell populations in the bronchoalveolar lavage fluid of atopic asthmatics after segmental allergen challenge. Allergy Asthma Clin Immunol 2013; 9: 37

23. Cho SH, Stanciu LA, Holgate ST, Johanston SL. Increased interleukin-4, interleukin-5, and interferon-gamma in airway CD4+ and CD8+ T cells in atopic asthma. Am J Respir Crit Care Med 2005; 171: 224-30.

24. Prabhakar U, Eirikis E, Reddy M, et al. Validation and comparative analysis of a multiplexed assay for the simultaneous quantitative measurement of Th1/Th2cytokines in human serum and human peripheral blood mononuclear cell culture supernatants. J Immunol Methods 2004; 291: 27-38. 